\title{
Etnomodelos no Ensino de Ciências: da Cultura Gaúcha à Iniciação Científica
}

\section{Etnomodelos en la educación científica: de la cultura gaúcha a la iniciación científica}

\author{
Jeruza Quintana Petrarca de Freitas (jeruza.quintana@gmail.com) \\ Universidade Federal do Pampa \\ Ângela Maria Hartmann (angelahartmann@unipampa.edu,br) \\ Universidade Federal do Pampa
}

\begin{abstract}
Resumo: O diálogo entre o conhecimento local e o conhecimento acadêmico é pautado no programa de pesquisa etnomodelagem. O programa proporciona a valorização de modelos desenvolvidos por membros de grupos culturais distintos para traduzir situações-problema retiradas da própria realidade. Considerando que existem conhecimentos culturais que não são valorizados, ou explorados, em práticas pedagógicas escolares ou acadêmicas, este artigo apresenta os resultados de uma pesquisa que buscou responder o seguinte problema: Quais etnomodelos vinculados à cultura gaúcha podem contribuir para a iniciação científica de estudantes da Educação Básica e ampliar sua alfabetização e cultura científica? Para elaboração dos etnomodelos, investigou-se o conhecimento científico presente em elementos da cultura gaúcha: o chimarrão, a esquila a martelo, o banho de gado, o alambrador, a mala de garupa e o jogo de bocha. Durante a investigação, foram realizadas entrevistas com professores universitários, que indicaram alguns dos conteúdos científicos que podem ser abordados em cada um deles no currículo escolar. Os seis etnomodelos reunidos a partir de costumes do povo do Estado do Rio Grande do Sul são descritos de forma detalhada e apresentados neste artigo em formato de mapas mentais. A partir desses etnomodelos, pretende-se produzir outra forma de trabalhar as Ciências e a Matemática.
\end{abstract}

Palavras-chave: Etnomodelagem; Ciências e Matemática; Educação Básica.

Resumen: El diálogo entre el conocimiento local y el conocimiento académico se basa en el programa de investigación del etnomodelado. El programa proporciona la mejora de modelos desarrollados por miembros de diferentes grupos culturales para traducir situaciones problemáticas tomadas de la realidad. Considerando que hay saberes culturales que no son valorados, ni explorados, en las prácticas pedagógicas escolares o académicas, este artículo presenta los resultados de una investigación que buscó dar respuesta a la siguiente problemática: ¿Qué etnomodelos vinculados a la cultura de Rio Grande do Sul pueden contribuir a la iniciación científica de los estudiantes de Educación básica y ampliar su alfabetización y cultura científica? Para la elaboración de los etnomodelos, se investigó el conocimiento científico presente en elementos de la cultura gaucha: el chimarrão, la ardilla con martillo, el baño de ganado, la alambrada, la maleta de grupa y el juego de petanca. Durante la investigación, se realizaron entrevistas con profesores universitarios, quienes indicaron algunos de los contenidos científicos que se pueden abordar en cada uno de ellos en el currículo escolar. Los seis 
etnomodelos recogidos de las costumbres de los habitantes del Estado de Rio Grande do Sul se describen en detalle y se presentan en este artículo en forma de mapas mentales. A partir de estos etnomodelos, se pretende producir otra forma de trabajar con Ciencias y Matemáticas.

Palabras claves: Etnomodelado; Ciencias e Matemática; Educación Básica.

\section{INTRODUÇÃO}

A cultura é composta por um conjunto de conhecimentos, crenças, símbolos e significados organizados em categorias e regras sobre as relações e os modos de interagir, que uma pessoa necessita conhecer para integrar-se a uma determinada sociedade (LARAIA, 2007). As ideias, os procedimentos e as práticas pertencentes a uma cultura, constituem, porém, um conhecimento distinto daquele usualmente estudado nas escolas. Assim sendo, nem todos os conhecimentos intrínsecos a diferentes etnias, comunidades e cultura são percebidos e valorizados ou considerados e explorados em práticas pedagógicas escolares e/ou acadêmicas de maneira geral.

Nesse contexto, a etnomodelagem assume o papel de promover a valorização de modelos desenvolvidos por membros de grupos culturais distintos, para traduzir situações-problema retiradas da própria realidade, conectando os aspectos culturais (etno) aos da Matemática acadêmica (modelagem) (CORTES; ROSA; OREY, 2017). Para facilitar $\mathrm{o}$ entendimento $\mathrm{e}$ a compreensão dos elementos culturais, a etnomodelagem apresenta os etnomodelos: "representações precisas e consistentes com o conhecimento científico e matemático socialmente construído, desenvolvido e compartilhado pelos membros desses grupos" (ROSA; OREY, 2017, p. 45).

A problematização de questões da realidade pode contribuir para a formação intelectual dos sujeitos, provocando o pensamento crítico, a análise de situações que podem gerar respostas fundamentadas e com significado para suas vidas (PRESTES; CAPELLETTO, 2008). Nesse mesmo sentido, Oliveira e Faltay (2019, p. 184) expõem que "é preciso associar ciência com os aspectos do próprio referencial que o aluno tem no dia a dia”. De acordo com Demo (2007), a forma mais eficaz de iniciar o processo de reconstrução do conhecimento é partindo da valorização do trajeto cultural, da base cultural própria do discente trazendo-o ao longo do processo como referência constante. 
“A cultura não é só memória e preservação. É também o chão do futuro feito com propriedade" (DEMO, 2007. p. 26).

De acordo com o programa de etnomodelagem, o conhecimento matemático local é desenvolvido pelos membros de grupos culturais distintos a partir de uma interpretação própria de sua cultura (abordagem êmica) em oposição à interpretação realizada pelos observadores externos (abordagem ética) (ROSA; OREY, 2012). Contudo, por meio da contextualização de atividades curriculares pautadas na etnomodelagem é possível traduzir as práticas desenvolvidas pelos membros de determinada cultura (CORTES; ROSA; OREY, 2017).

"Etnomodelos são representações precisas e consistentes com o conhecimento científico e matemático socialmente construído, desenvolvido e compartilhado pelos membros desses grupos" (ROSA; OREY, 2017, p. 45). O principal objetivo para a elaboração dos etnomodelos é traduzir os construtos êmicos para o estabelecimento de relações entre o conhecimento conceitual local e as práticas matemáticas inseridas nele (ROSA; OREY, 2017). Nessa perspectiva, a abordagem dialógica (êmica-ética) possui o propósito de estabelecer interação entre os construtos ético e êmico. Essa interação se dá pela tradução realizada de forma holística, por grupos externos, das práticas matemáticas do grupo em estudo, para que grupos culturais diferentes possam compreender e explicar, sob o ponto de vista dos outsiders, o conhecimento matemático de um grupo cultural específico (ROSA; OREY, 2017).

Cientes de que o conceito tem origem na área de Matemática, destacamos, neste trabalho, uma variação que, sem perder as propriedades balizadoras da etnomodelagem, visa abranger as áreas das Ciências e da Matemática. Buscando articular essas duas áreas, tem-se o intuito de responder o seguinte problema de pesquisa: Quais etnomodelos vinculados à cultura gaúcha podem contribuir para a iniciação científica de estudantes da Educação Básica e ampliar sua alfabetização e cultura científica?

Ressaltamos que os etnomodelos investigados e descritos neste trabalho possuem o intuito de indicar a conexão existente entre o conhecimento científico e a cultura gaúcha, buscando nos costumes e atividades do povo do Estado do Rio Grande do Sul, outra forma de trabalhar as Ciências e a Matemática na Educação Básica.

Existe "uma coevolução entre a cultura do gaúcho e o sistema de campos atual do bioma Pampa" (CRUZ e GUADAGNIN, 2010, p. 9), pois tanto o meio (a fauna e a 
flora do bioma Pampa) como o homem (gaúcho) contribuem para a formação dessa cultura. Essa coevolução do gaúcho e do Pampa está rompendo com a transição da estância para o sistema de granja, devido às grandes plantações de soja e a criação de gado em confinamento. O patrimônio cultural corre risco de deterioração. Contudo, essa deterioração só "não é maior porque ainda existem fortes movimentos culturais (tradicionalismo) e ainda sobrevivem práticas tradicionais em algumas propriedades" (CRUZ; GUADAGNIN, 2010, p. 10).

Um exemplo de artefato cultural gaúcho é a tália/talha apresentada na figura 1. A talha, utilizada para contar o rebanho, é um instrumento formado por uma corda de couro trançada e contas de metal ou de osso. Cada conta da talha pode representar 10 , 50 ou 100 animais. A escolha do valor da conta fica sujeita ao tamanho do rebanho e ao conhecimento numérico do peão. Esse sistema de contagem era comum em épocas latifundiárias, em que não havia delimitações de terra e vários fazendeiros compartilhavam o mesmo local para a criação de bovinos ou equinos.

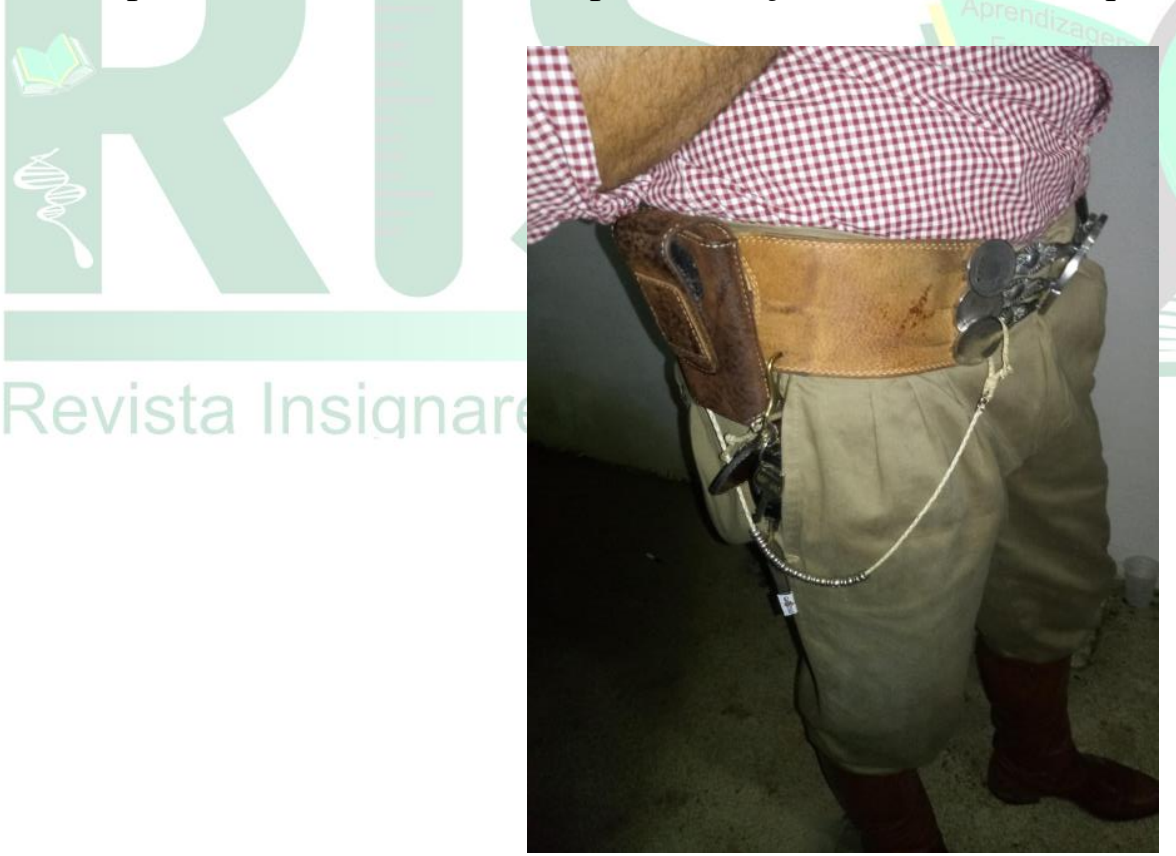

Figura 1 - Talha presa à cintura de um peão. Fonte: acervo de Freitas (2019)

A escolha dos materiais - couro e osso - se dá pela sua abundância na região da campanha. O couro e os ossos dos animais mortos era artigo numeroso, pois, como não havia um tratamento intensivo para as doenças do rebanho, muitos animais acabavam morrendo. Já a carne dos animais saudáveis era um dos principais pratos dos trabalhadores rurais e o charque a principal fonte de economia. 
Atualmente, estamos habituados com o sistema decimal, que não se diferencia tanto do sistema utilizado pela talha. Ocorre, porém, uma mudança de base quase imperceptível. O peão, por exemplo, ao encontrar 155 reses, dependendo da base que escolher para seus cálculos de contagem, poderá fazer o cálculo ilustrado no Quadro 1:

Quadro 1 - Exemplos de base de contagem

\begin{tabular}{|l|c|l|c|}
\hline Base 10 & $\begin{array}{c}10+10+10+10+10+10+10+10+10+10+10+10+ \\
10+10+10+5\end{array}$ & 15 contas mais 5 reses & $15 \times 10+5$ \\
\hline Base 50 & $50+50+5$ & 2 contas mais 5 & $2 \times 50+5$ \\
\hline Base 100 & $100+55$ & 1 conta mais 55 & $1 \times 100+55$ \\
\hline
\end{tabular}

Fonte: Freitas (2019)

Essa forma de calcular, além de envolver as operações de adição e multiplicação, possibilita ao usuário uma adaptação do material de contagem (talha), conforme seus conhecimentos matemáticos.

Além do compromisso de registrar e valorizar práticas como o banho de gado e a esquila a martelo, ultrapassadas por tecnologias melhoradas, mas que merecem ser inventariadas e ter seus fundamentos científicos explicados, a realização desta pesquisa possui um objetivo pedagógico: o de contribuir para a alfabetização e a iniciação científica de estudantes da Educação Básica.

Chassot (2003) considera que, nos últimos vinte anos do século vinte, o ensino de ciências esteve centrado na mera aquisição de conhecimentos por parte dos alunos. Entretanto, hoje já não se concebe um modelo de ensino que não leve em consideração os aspectos sociais e pessoais do discente (CHASSOT, 2003). Atualmente, é imprescindível que os cidadãos sejam cientificamente letrados e dotados de noções de como a ciência funciona, o que fez com que se abandone, gradualmente, um tipo de currículo que apenas detenha fatos a aprender (WARD et al., 2010).

A expressão "alfabetização científica" possui um pluralismo semântico na literatura nacional: "Letramento Científico", "Alfabetização Científica" e "Enculturação Científica", porém todos com uma preocupação comum: a formação cidadã das pessoas para ação e atuação em sociedade. Nesse sentido, a alfabetização científica proporciona uma nova forma de ver e modificar o mundo, bem como de modificar a si próprio (SASSERON; CARVALHO, 2011). 
A expressão Enculturação Científica utilizada por Carvalho e Tinoco (2006) e Mortimer e Machado (1996), parte do pressuposto que o Ensino de Ciências deva proporcionar condições para que os alunos além das suas próprias culturas passem a incorporar também as noções, ideias, e conceitos científicos, desenvolvendo assim habilidades para a participação de debates desta cultura (SASSERON, 2008).

Chassot (2003, p. 91) defende que a pessoa alfabetizada cientificamente é capaz de entender a linguagem escrita pela natureza, tendo capacidade para controlar e prever as transformações que ocorrem na natureza. Furió et al. (2001, apud CHASSOT, 2003) apresenta a alfabetização científica como uma possibilidade de a população, compreendendo as relações complexas entre ciência e sociedade, dispor de conhecimentos científicos e tecnológicos, que contribuam para a resolução de problemas e o atendimento de suas necessidades de saúde e de sobrevivência básica.

Ao examinar o texto das áreas do conhecimento de Matemática e Ciências Naturais, na Base Nacional Comum Curricular (BNCC), observamos o uso da expressão letramento matemático como aquele "que assegura aos alunos reconhecer que os conhecimentos matemáticos são fundamentais para a compreensão e a atuação no mundo" (BRASIL, 2017, p. 268). Já o letramento científico é definido como "a capacidade de compreender e interpretar o mundo (natural, social e tecnológico), mas também de transformá-lo com base nos aportes teóricos e processuais das ciências" (idem, 2017, p. 323).

Outras dimensões para a Alfabetização Científica são citadas por Sasseron (2008) no sentido de que mais importante que saber a ciência em sua totalidade, a pessoa alfabetizada cientificamente necessita saber interpretar as implicações do conhecimento científico na sociedade. A autora reúne, no que denomina Eixos Estruturantes, as conceituações do que seja a alfabetização científica e que balizam o modo como o ensino de Ciências pode ser promovido: (i) compreensão básica de termos; (ii) conhecimentos e conceitos científicos fundamentais; (iii) compreensão da natureza das ciências e dos fatores éticos e políticos que circundam sua prática; (iv) entendimento das relações existentes entre ciência, tecnologia, sociedade e meio-ambiente.

Hartmann (2012), por sua vez, elenca sete indicadores de cultura científica, que consideramos importante serem analisados em um processo de iniciação científica, uma vez que ampliam a concepção de alfabetização científica. São eles: 1) Dominar 
Edição Especial: I SSAPEC - Simpósio Sul-Americano de Pesquisa em Ensino de Ciências

ISSN: 2595- $4520 \quad$ Vol. 4, n. 3. 2021

gradualmente um vocabulário básico de conceitos científicos; 2) Compreender ciência e tecnologia como um conhecimento com regras, códigos e convenções específicas; 3) Compreender ciência e tecnologia como parte da cultura e da realidade cotidiana; 4) Compreender o impacto da ciência e da tecnologia sobre os indivíduos e a sociedade; 5) Usar o conhecimento científico e tecnológico de forma crítica e consciente; 6) Compreender ciência e tecnologia como um conhecimento a ser construído em uma perspectiva interdisciplinar; 7) Usar a pesquisa como instrumento metodológico de renovação permanente do conhecimento científico e da produção tecnológica.

De acordo com Pavão e Freitas (2008), é necessário o professor desfocar de aulas pautadas na memorização e focar na promoção da investigação, experimentação e discussão. Diferentemente de seguir roteiros preestabelecidos, "fazer ciência na escola é utilizar procedimentos próprios da ciência como observar, formular hipóteses, experimentar, registrar, sistematizar, analisar, criar e transformar o mundo" (PAVÃO; FREITAS, 2008, p. 15).

Existe, porém, um pensamento conservador de que criança não possui capacidade de fazer ciência e uma concepção de que, para ser cientista, determinados requisitos devem ser cumpridos. Uma vez que fazer ciência na escola não é descobrir uma nova lei, nova fórmula, nova teoria, essa visão, para Pavão e Freitas (2008), é preconceituosa, pois há diversos trabalhos publicados relatando experiências bem sucedidas de professores e alunos realizando atividades científicas em feiras de ciências, por exemplo. Ao quebrar esta visão preconceituosa, consideramos os estudantes-cientistas como cidadãos que terão como principal característica de sua formação serem capazes de responder às emergências do mundo atual (PAVÃO; FREITAS, 2008).

Na dimensão do como fazer do saber acadêmico um saber escolar e como fazer do saber popular um saber escolar, Chassot (2003, p. 97) aposta em um ensino com uma visão holística, "um ensino de ciências que contemple aspectos históricos, dimensões ambientais, posturas éticas e políticas, mergulhadas na procura de saberes populares e nas dimensões das etnociências". O autor também elucida que esse tipo de proposta favorece uma alfabetização científica mais significativa. Essa concepção de ensino de ciências culmina com o propósito desta pesquisa que visa explorar os saberes populares da cultura gaúcha e traduzi-los em saberes escolares. Ao propor a inserção dos etnomodelos, criados a partir desta pesquisa no currículo escolar, espera-se contribuir 
Edição Especial: I SSAPEC - Simpósio Sul-Americano de Pesquisa em Ensino de Ciências

com a iniciação científica de estudantes da Educação Básica em regiões onde a cultura gaúcha está presente.

A iniciação científica compreende a inserção do aluno no mundo da pesquisa, e para aprender a fazer pesquisa os discentes precisam de orientação em seu percurso. A partir de trabalhos como os de Demo (2014), Ovigli (2014), Pinzan e Lima (2014), foram elaborados indicadores de que o aluno está se apropriando dos princípios da iniciação científica:

- Saber formular problemas;

- Ter iniciativa para buscar evidências para aspectos investigados;

- Apropriar-se da linguagem própria dos conceitos científicos;

- Interpretar dados de pesquisa;

- Encontrar caminhos para sua investigação (metodologia);

- Adotar uma expressão escrita autoral, com posicionamento crítico;

- Comunicar-se apresentando argumentos.

Para promover a iniciação científica de estudantes da Educação Básica, foi planejada uma oficina intitulada "Etno's Pampa", dividida em cinco módulos:

Módulo 1 - Introdução à cultura gaúcha e científica;

Módulo 2 - Fontes de consulta científica: onde encontro?;

Módulo 3 - Formas de obter os próprios dados;

Módulo 4 - Análise dos dados;

Módulo 5 - Divulgação da pesquisa.

Os resultados dessa oficina serão discutidos em trabalho futuro. Destacamos neste artigo apenas os seis etnomodelos criados a partir da investigação sobre o conhecimento científico presente nos seguintes elementos da cultura gaúcha: o chimarrão, a esquila a martelo, o banho de gado, o alambrador, a mala de garupa e o jogo de bocha.

\section{METODOLOGIA}

Para responder o problema de pesquisa, foi desenvolvida uma pesquisa exploratória a fim de verificar as potencialidades de associação de conceitos científicos das Ciências e da Matemática a elementos do cotidiano dos sul-rio-grandenses (gaúchos). O primeiro passo, foi elencar artefatos e hábitos culturais da região do 
Edição Especial: I SSAPEC - Simpósio Sul-Americano de Pesquisa em Ensino de Ciências ISSN: 2595- $4520 \quad$ Vol. 4, n. 3. 2021

Pampa que apresentam potencialidades de associação com o conhecimento científico, o que envolveu consultas informais a pessoas que vivenciam fortemente a cultura gaúcha.

Em seguida, foram entrevistados professores da Universidade Federal do Pampa UNIPAMPA, das áreas de Química, Física, Biologia e Matemática, solicitando-lhes que apontassem elos entre esses elementos e o conhecimento científico. As relações e as indicações desses docentes foram utilizadas para elaborar os etnomodelos.

\section{RESULTADOS E DISCUSSÕES}

São descritos, a seguir, os seis etnomodelos elaborados: o chimarrão, a esquila a martelo, o banho de gado, o alambrador, a mala de garupa e o jogo de bocha. Após uma breve descrição do artefato ou hábito cultural que constitui o etnomodelo, são destacados, em um mapa mental, os conteúdos levantados durante a pesquisa e que apresentam potencial de serem abordados na Educação Básica. Na sequência, são indicadas as áreas de conhecimento do currículo escolar que abordam esses conteúdos.

\subsection{Etnomodelo Chimarrão}

Da infusão da erva-mate, devidamente processada, é preparado o chimarrão. Aos quíchuas, povos aborígines do Peru, vincula-se o mais remoto uso da erva-mate. Em seu vocábulo, "mati" tem significado de cuia, porongo, cabaça, isto é, o objeto no qual é bebida a infusão, apresentado na figura 2. Durante os primeiros anos de colonização do Peru, muitos apoiaram a proibição do seu consumo devido ao rumor de causar danos à saúde, de viciar e promover um mau costume e até mesmo por ser considerada a "erva do diabo" pelos seus efeitos afrodisíacos, entre outras considerações. Porém os boatos dos malefícios não surtiram efeito já que o pecado virou um convite à tentação (BOGUSZEWSKI, 2007). 


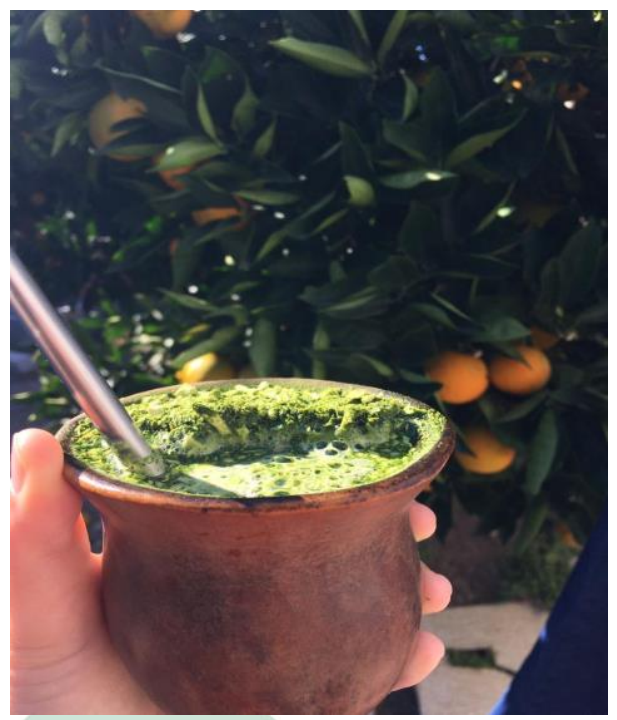

Figura 2 - Chimarrão feito em cuia de porongo e bomba de metal. Fonte: Freitas (2020)

Com a chegada dos espanhóis ao Paraguai, o hábito de tomar a infusão espalhouse por toda a região sul do continente. As missões jesuíticas estabeleceram-se na maior parte do território de origem da erva-mate e apesar do apelo inicial pela também proibição do consumo, foram eles os responsáveis pelo aperfeiçoamento do cultivo, aumento da produção, comércio e exportação da planta (BOGUSZEWSKI, 2007).

A descrição científica da planta é devida ao botânico e naturalista francês Auguste de Saint-Hilaire (1779-1853) que, após o estudo da erva-mate, a nomeou de Ilex paraguariensis. "Por tratar-se de uma planta nativa, o consumo do mate criou fronteiras geográficas próprias e, de certa maneira, funcionou no passado, tanto quanto hoje, de elo cultural entre os povos dos diferentes países da região sul” (BOGUSZEWSKI, 2007, p. 22). A Figura 3 apresenta o mapa mental construído a partir das indicações dos professores universitários entrevistados: 


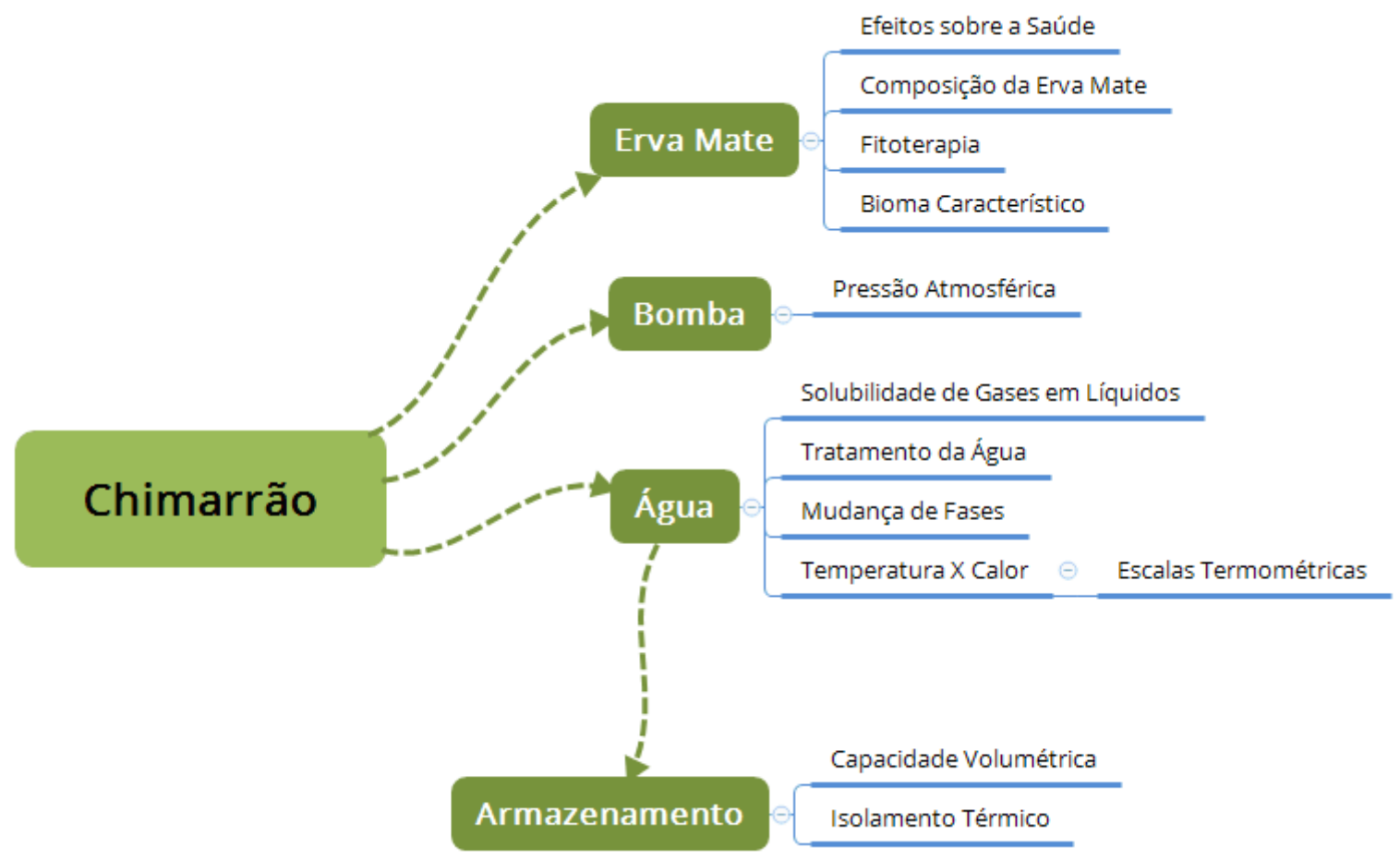

Figura 3 - Mapa mental Chimarrão. Fonte: Freitas (2020)

A partir do etnomodelo Chimarrão é possível abordar diversos assuntos que contemplam conceitos científicos na Matemática como a determinação da capacidade volumétrica da garrafa térmica, cambona ou chaleira; na Física, a pressão atmosférica que atua quando se bebe a infusão com o auxílio da bomba, a diferença entre os conceitos de temperatura e calor, as escalas termométricas; na Biologia, o bioma característico da erva-mate, os efeitos sobre a saúde, sendo o chimarrão uma das possíveis causas do câncer de esôfago, entre outras enfermidades, ao mesmo tempo em que é usada como princípio ativo na fitoterapia; na Química, expõe a mudança de fases, tratamento da água, composição da erva-mate, solubilidade dos gases em líquidos. Certamente vários assuntos são abordados por mais de uma componente curricular: bioma (Geografia e Biologia); pressão atmosférica (Física e Química); tratamento da água (Biologia e Química); temperatura e calor (Física e Química).

\subsection{Etnomodelo Banho de Gado}

O segundo etnomodelo é o do Banho de Gado, antigamente utilizando-se da imersão, tem por objetivo a limpeza corporal do animal. Os animais (bois, terneiros, vacas e touros) passam pelo banheiro, apresentado na figura 4, uma espécie de piscina 
contendo partes proporcionais de água e ativos (carrapaticidas etc.), visando eliminar os parasitas externos (berno, carrapato, sarna, mosca do chifre etc) do rebanho.

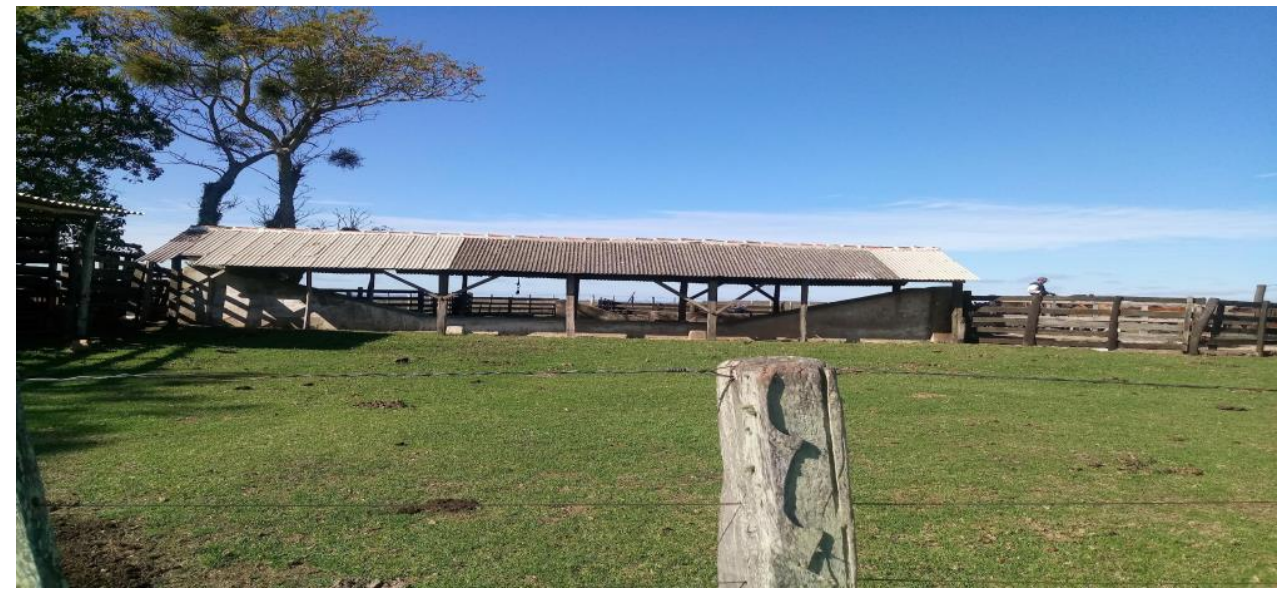

Figura 4 - Local do Banho de Gado. Fonte: Freitas (2020)

O mapa mental representado na Figura 5 destaca alguns dos conceitos científicos que podem ser estudados a partir do etnomodelo Banho de Gado:

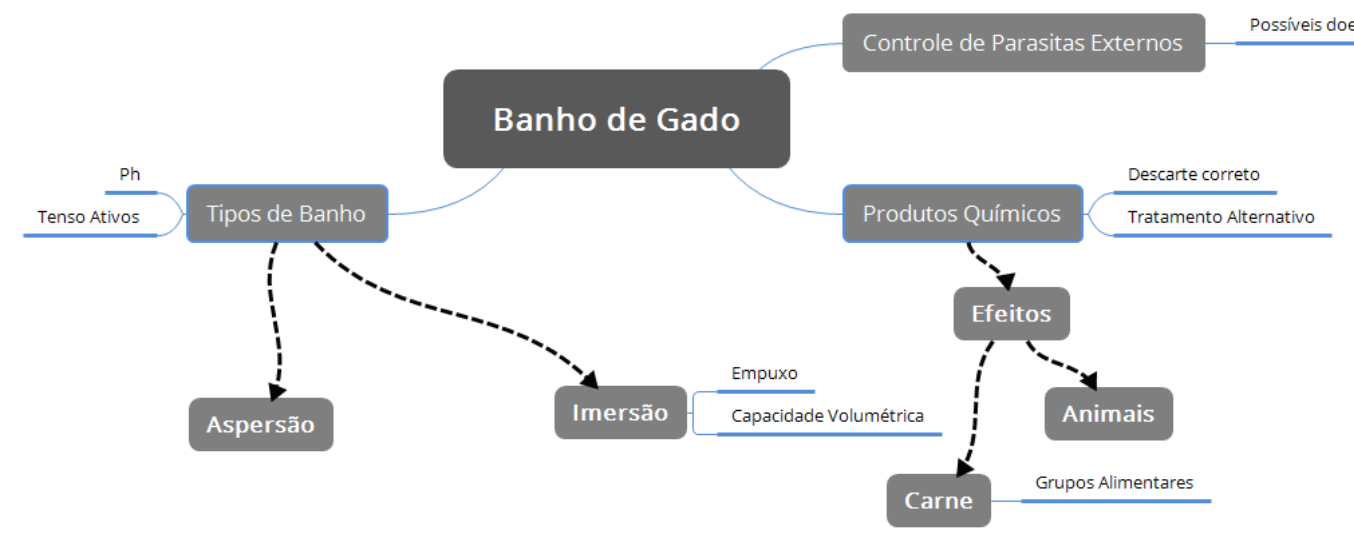

Figura 5 - Etnomodelo Banho de Gado. Fonte: Freitas (2020)

Esse etnomodelo propicia o estudo dos seguintes conceitos científicos: na Química, o Ph alcalino para o banho, o uso de tensoativos, que auxiliam na redução da tensão superficial, a composição química da carne; na Física, o empuxo, que age para o animal flutuar e nadar até a área de secagem; na Matemática, a capacidade volumétrica da "piscina"; na Biologia, as possíveis doenças transmissíveis aos animais pelos parasitas externos, descarte correto das embalagens e dos produtos químicos utilizados e a disponibilidade de tratamentos alternativos para a substituição de produtos químicos. 


\subsection{Etnomodelo Esquila a Martelo}

A expressão "a martelo" deriva do som emitido pela tesoura durante a esquila. Essa prática, ilustrada na figura 6 (esquerda), visa à tosa dos ovinos, com o intuito de comercialização da lã retirada dos animais. Em tempos idos, a lã era considerada moeda de troca nos armazéns, onde os criadores levavam sua produção anual como pagamento pela retirada de mantimentos.
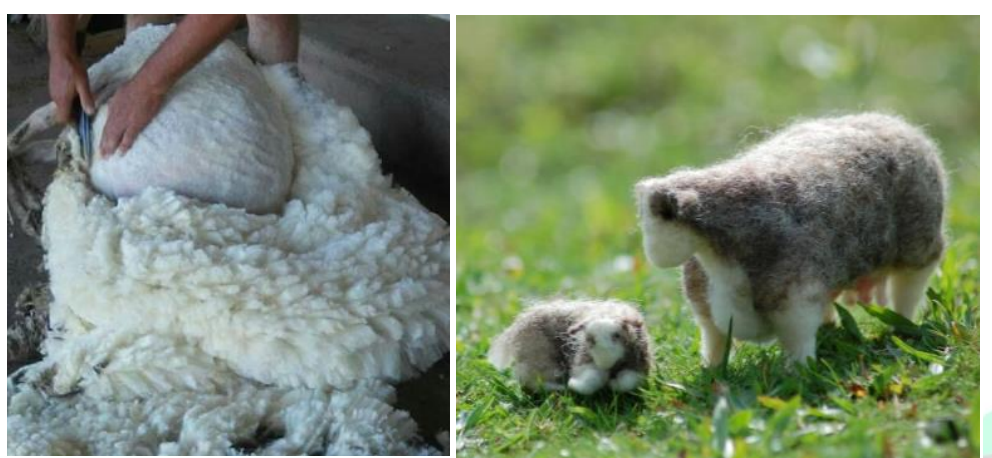

Figura 6 - Esquila à martelo e artesanato produzido em lã. Fonte: Freitas (2020)

Ademais, é de cultura local a utilização da lã para confecção de artesanato, como exemplo a figura 6 (direita) ilustra a confecção de peça em lã representando uma vaca e seu terneiro. Para que se chegue à lã como matéria final, a lã crua passa por processos como o de "cardar", que nada mais é do que abrir a lã. Depois da lã aberta, faz-se o fio, utilizando uma roca. $\mathrm{O}$ fio, por sua vez, é enrolado no fuso até que se forme o novelo.

A Figura 7 apresenta o mapa mental criado a partir do etnomodelo Esquila a Martelo, considerando os conceitos científicos que podem ser estudados a partir dele.

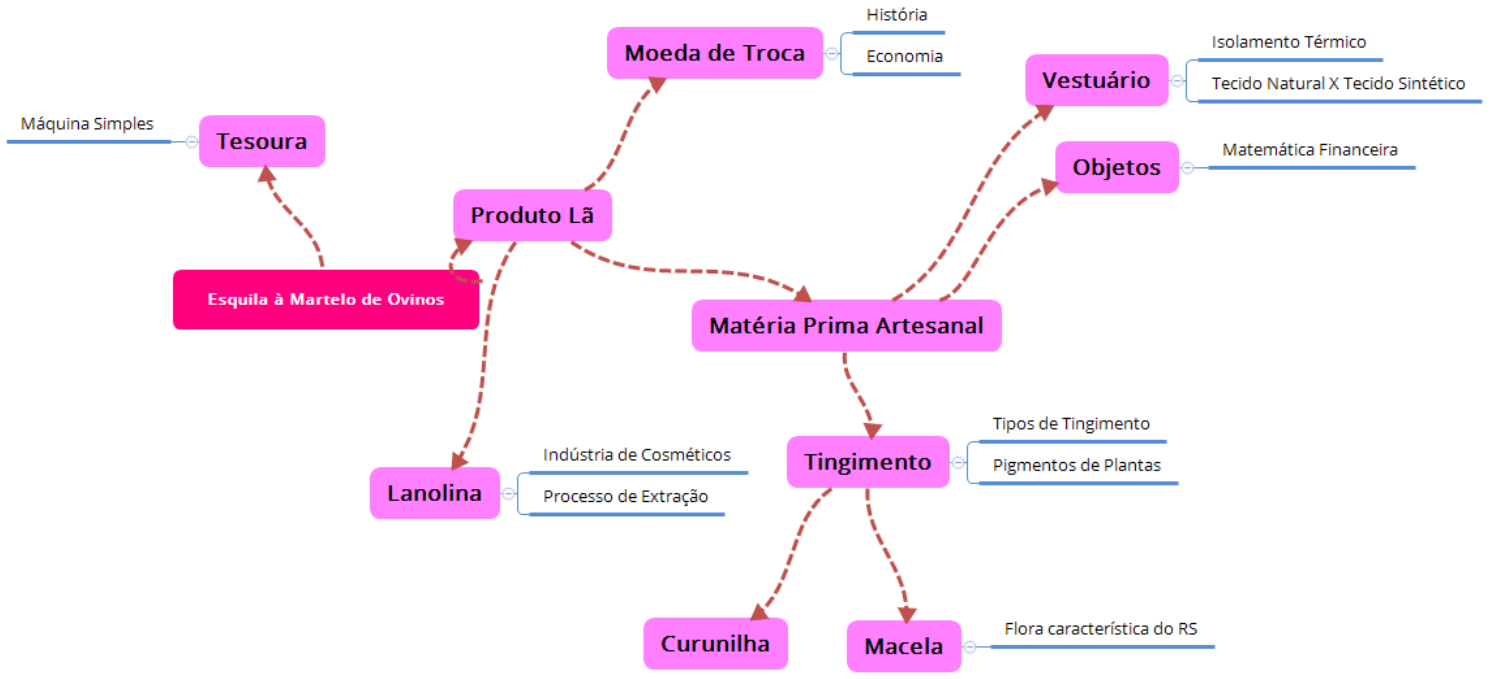

Figura 7 - Etnomodelo Esquila a Martelo de Ovinos. Fonte: Freitas (2020)

Recebido em: 18/01/2021 
No etnomodelo Esquila a Martelo, é possível destacar conhecimentos científicos como: na Biologia, a flora característica do RS, de onde são extraídos pigmentos para o tingimento da lã; na Física, o estudo de máquinas simples como a tesoura utilizada somente para a esquila; na Matemática financeira, o valor a ser atribuído aos objetos confeccionados artesanalmente, a venda da lã que varia conforme sua espécie e valor do dólar; na Química, a diferença existente entre o tecido sintético do tecido natural; na História, a economia gerada pela lã utilizada como moeda de troca na região da campanha; na área da Física e Química, o isolamento térmico e o processo de extração da lanolina, muito utilizada na indústria de cosméticos.

\subsection{Etnomodelo Alambrador}

Alambrador, nome do profissional que trabalha no cercamento das propriedades rurais, utilizando moirões, tramas e arame para demarcação de terras e evitar a fuga dos animais das propriedades, é mais um etnomodelo. Profissão artesanal, representada na figura 8, que pode ser considerada em extinção, por ser transmitida de geração em geração, visto que não há curso técnico para tal formação.

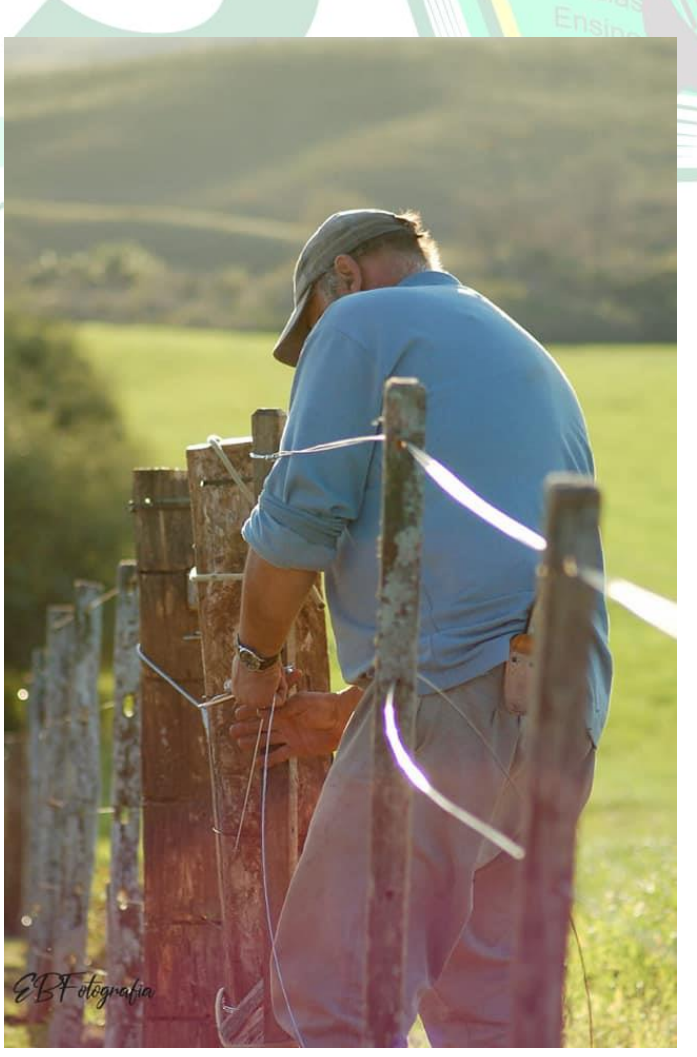

Figura 8 - Alambrador esticando arame. Fonte: Freitas (2020) 
A partir desse etnomodelo, é possível explorar os conceitos científicos, esboçados na figura 9.

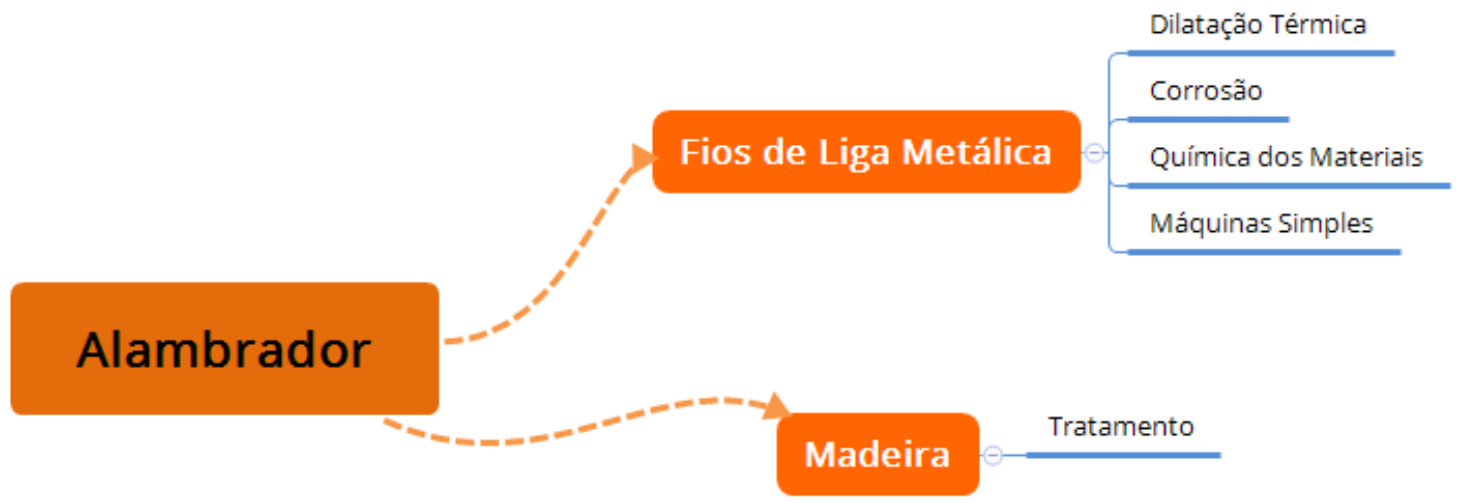

Figura 9 - Mapa Mental Alambrador. Fonte: Freitas (2020)

Na Química, a corrosão dos fios de liga metálica, o porquê de o processo de oxidação ser mais demorado nos arames atuais em vista dos antigos, pergunta esta a ser respondida pela química dos materiais, bem como o tratamento realizado na madeira para proteção de pragas e apodrecimento; na Física, também é possível desenvolver o trabalho com máquinas simples devido à ferramenta utilizada para esticar o arame.

\subsection{Etnomodelo Mala de Garupa}

A mala de garupa, apresentada na figura 10, é uma espécie de bolsa usada para o transporte de objetos como os apetrechos do gaúcho para a lida campeira ou as bergamotas encontradas em uma tapera velha. Por ser transportada no lombo do cavalo (ou garupa) é que se denominou mala de garupa. Sabe-se que, no passado, eram confeccionadas em couro cru, mas, atualmente, são em tecido resistente e escuro, como o brim, para evitar que o suor do cavalo a desgaste e para não aparentar as manchas de sujeira. 


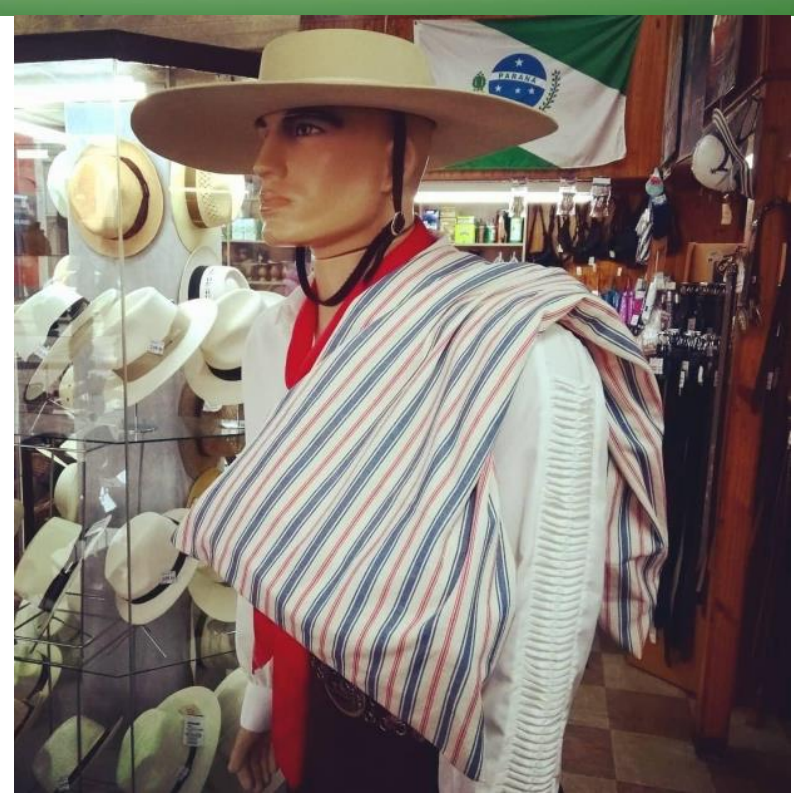

Figura 10 - Mala de garupa no ombro do manequim. Fonte: https://www.facebook.com/csatitoschier/photos/mala-de-garupa-mala-garupa-gaucho-pilcha-acessoriocasatito-curitiba-parana-bras/2428004293892839/

A mala de garupa em formato de saco é costurada nas extremidades, sendo aberta uma fenda no meio do tecido superior, permitindo a colocação de objetos. Depois de alçada no lombo do cavalo ou ao ombro do peão, esse formato de mala não deixa cair os objetos durante o movimento do transporte. Pala e Poncho são vestimentas típicas do povo gaúcho, tanto urbano quanto rural, sendo utilizados por cima da roupa como se fosse um casaco. As duas vestimentas possuem uma abertura bem ao meio para ser passada a cabeça. O tecido fica apoiado nos ombros e apresenta diferenças em seu tamanho. Na região da fronteira oeste do Rio Grande do Sul se faz distinção entre pala e poncho. O pala vai dos ombros até a altura dos quadris e o poncho dos ombros até abaixo dos joelhos ou na altura das canelas.

O pala utilizado para dias frios e como cobertor improvisado é confeccionado de forma tradicional artesanalmente em lã crua e industrialmente comercializado com fibras sintéticas de forma retangular pode possuir franjas e gola. O poncho, além do frio, protege da chuva, atualmente produzido em tecidos impermeáveis (borracha, napa, entre outros), em formato circular ou ovalado a sua forma tradicional de confecção é em lã grossa forrado de baeta. Não possui franjas e, necessariamente, tem gola alta abotoada. A figura 11 apresenta possíveis conhecimentos científicos de serem trabalhados na Educação Básica a partir do etnomodelo mala de garupa e pala e poncho. 


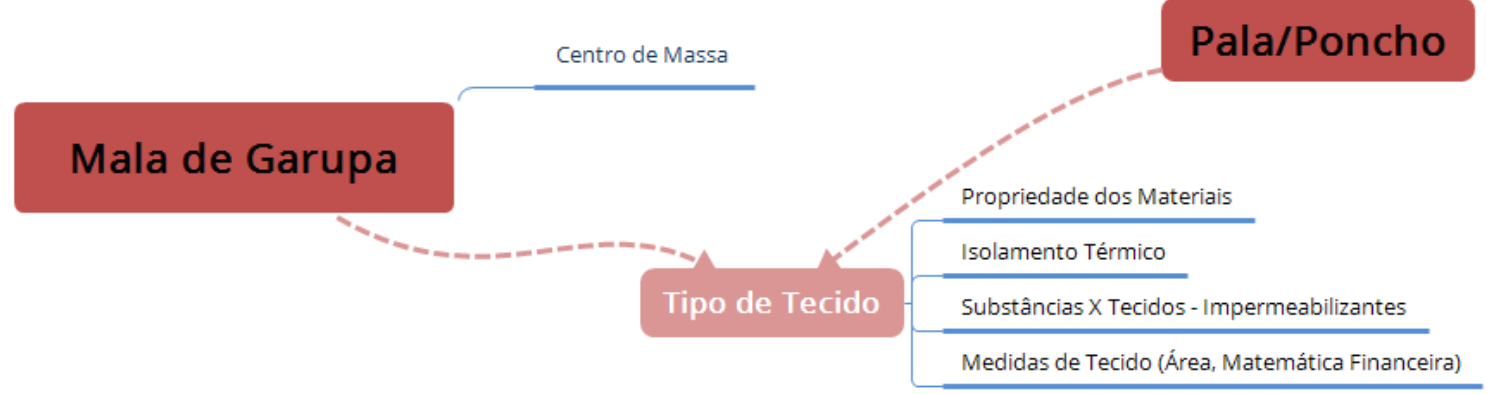

Figura 11 - Etnomodelo Mala de Garupa. Fonte: Freitas (2020)

Os conhecimentos científicos relacionados com o etnomodelo Mala de Garupa, Pala e Poncho são: na Química, a propriedade dos materiais e as substâncias que produzem a impermeabilidade do poncho, bem como o isolamento térmico percebido ao utilizar o pala ou o poncho; na Matemática, as medidas de tecidos necessárias para a confecção dos artefatos, os valores despendidos e, caso ocorra a comercialização, o preço final do produto para que se obtenha lucro; na Física, o centro de massa se faz necessário na medida em que se deve apoiar a mala de garupa no cavalo ou no ombro de modo que não fique um lado mais pesado que o outro.

\subsection{Etnomodelo Jogo de Bocha}

O Jogo de Bocha é praticado em um local denominado cancha, de formato retangular, com limitações feitas de tábuas. $\mathrm{O}$ piso pode variar de terra batida, saibro ou material sintético. A bocha refere-se à "bola" utilizada no jogo, confeccionada de madeira ou material sintético. Essa atividade esportiva do gaúcho possibilitou destacar conceitos científicos, ilustrados na figura 12 :

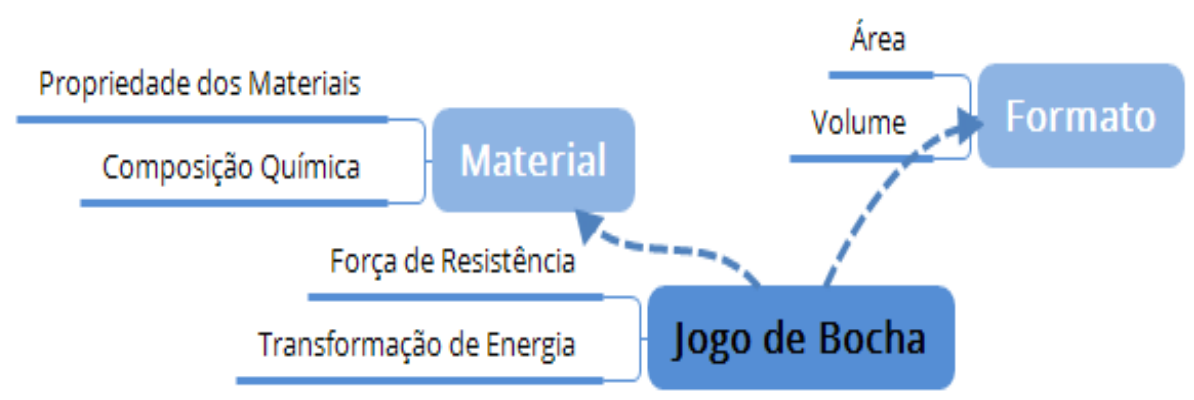

Figura 12 - Etnomodelo Jogo de Bocha. Fonte: Freitas (2020) 
$\mathrm{Na}$ Química, a propriedade dos materiais tanto da cancha quanto da bocha e consequentemente sua composição química; na Física, a força de resistência ao lançar a bocha e a transformação da energia que ocorre nesse momento; na Matemática, área e volume.

Ressalta-se que os etnomodelos aludem à abordagem êmica e ética, sendo que:

\begin{abstract}
A abordagem ética pode ser considerada a visão externa dos observadores, que estão olhando de fora, em uma postura transcultural, comparativa e descritiva, enquanto a abordagem êmica pode ser definida como a visão interna dos observados, que estão olhando de dentro, em uma postura cultural própria, particular e prescritiva. (ROSA; OREY, 2014, p. 135).
\end{abstract}

Os etnomodelos elaborados não possuem a característica da dialogicidade, em virtude de não ter sido realizada uma tradução das práticas locais, mas um inventário descritivo sobre cada elemento cultural e suas possíveis articulações com os conteúdos, que podem ser abordados nos componentes curriculares de Ciências e Matemática de diversos anos da Educação Básica.

\title{
4. CONCLUSÃO
}

A investigação para compor os etnomodelos evidencia que existem diversos conceitos científicos que explicam vivências e situações relacionadas à cultura gaúcha com potencial para o desenvolvimento de estudos curriculares na Educação Básica.

Em um primeiro olhar, o artefato de uma cultura pouco enuncia das possibilidades de explorar o conhecimento científico ou indica exclusividade de estudo de uma área específica do conhecimento. Dotados de raízes culturais, artefatos e hábitos demandam uma abordagem holística. Desta forma, para uma tradução apropriada à linguagem acadêmica, é recomendável que seu estudo seja pautado em diversas áreas do conhecimento científico.

Isto posto, é possível afirmar que os etnomodelos reunidos nesta pesquisa são capazes de interligar elementos da cultura gaúcha a diversos conceitos científicos. Espera-se que as atividades pedagógicas realizadas a partir deles contribuam com o processo de aprendizagem de Ciências e Matemática, em uma perspectiva que valorize o contexto e as práticas cotidianas dos estudantes e/ou de seus familiares. 
Esta pesquisa pretende, ainda, contribuir para o processo de iniciação científica de alunos da Educação Básica, desenvolvendo neles a capacidade de compreender conhecimentos científicos que explicam situações cotidianas. Almejamos que os discentes não só reconstruam seus saberes cotidianos como também sua realidade a partir de uma perspectiva cultural embasada em conhecimentos científicos.

\section{REFERÊNCIAS}

BRASIL. Base Nacional Comum Curricular. Brasília: MEC, 2017. Disponível em: $<$ http://basenacionalcomum.mec.gov.br/images/BNCC_EI_EF_110518_versaofinal_site .pdf>. Acesso em: 04 nov. 2019.

BOGUSZEWSKI, José Humberto. Uma História Cultural da Erva-Mate: o alimento e suas representações. Dissertação (Pós-graduação) - Instituto de Ciência Universidade Federal do Paraná, Curitibá, Paraná, 2007.

CHASSOT, Attico. Alfabetização científica: uma possibilidade para a inclusão social. Revista Brasileira de Educação. n. 22, jan./fev./mar./abr. 2003.

CORTES, Diego Pereira de Oliveira; ROSA, Milton; OREY, Daniel Clark. Traduzindo Dialogicamente as Práticas Laborais de um Feirante por meio da Etnomodelagem.

Boletim do Laboratório de Educação Matemática da FEUFF. Niterói, Rio de Janeiro, v. 8, n. 17, jan. /jun. 2017.

CRUZ, Rafael Cabral, GUADAGNIN, Demétrio Luis. Uma pequena história ambiental do Pampa: proposta de uma abordagem baseada na relação entre perturbação e mudança In: A sustentabilidade da Região da Campanha-RS: Práticas e teorias a respeito das relações entre ambiente, sociedade, cultura e políticas públicas. Santa Maria, RS:

UFSM, PPG Geografia e Geociências, Dep. de Geociências, 2010, p. 155-179.

DEMO, Pedro. Educação e alfabetização científica. São Paulo: Papirus Editora, 2014.

DEMO, Pedro. Educação pela Pesquisa. São Paulo: Autores Associados, 2007.

DOMINGUES, Edina; MACIEL, Maria Delourdes. Feira de Ciências: o despertar para o ensino e aprendizagem, v. 14, n. 18, 2011.

DORNFELD, Carolina Buso; MALTONI, Kátia Luciene. A Feira de Ciências como auxílio para a formação inicial de professores de ciências e biologia. Revista

Eletrônica de Educação. São Carlos, SP: UFSCar, v. 5, no. 2, p.42-58, nov. 2011.

FREITAS, Jeruza Quintana Petrarca. Etnomodelos da cultura gaúcha para o Ensino de Ciências: da iniciação científica à Feira de Ciências. 2020. 70 p. Projeto de Dissertação (Mestrado Profissional em Ensino de Ciências) - Universidade Federal do Pampa, Caçapava do Sul, RS, 2020.

Aceito em: 24/02/2021 
HARTMANN, Ângela Maria. O Pavilhão da Ciência: a participação de escolas como expositoras na Semana Nacional de Ciência e Tecnologia. 2012. 311 p. Tese (Doutorado em Educação) - Universidade de Brasília, Brasília, 2007. Disponível em: https://repositorio.unb.br/handle/10482/11254 Acesso em: 10 maio 2020

LARAIA, Roque de Barros. Cultura: um conceito antropológico. Rio de Janeiro: Zahar, 2007.

OLIVEIRA, Antonio José Silva; FALTAY, Paulo. Breve relato da política da divulgação científica no Brasil. In: PAVÃO, Antônio Carlos; FREITAS, Denise de (Org.). Quanta ciência há no ensino de ciências. São Carlos: EDUFSCAR, 2019. p. 181-187.

OVIGLI, Daniel Fernando Bovolenta. Iniciação científica na educação básica: uma atividade mais do que necessária. Revista Brasileira de Iniciação Científica, v. 1, n. 1, p. 78-90, 2014.

PAVÃO, Antônio Carlos, FREITAS, Denise de. Quanta Ciência há no Ensino de Ciências. Edufscar, São Carlos-SP: 2008.

PINZAN, Mariele Eloísa; LIMA, Albertina Pimentel. Iniciação Científica na Educação Básica: uma possibilidade de democratização da produção científica. IX EPCTEncontro de Produção Científica e Tecnológica. Campo Mourão, v. 27, 2014.

PRESTES, Michely; CAPELLETTO, Eliane. Aprendizagem significativa no ensino de Física das radiações: contribuições da educação ambiental. Revista Eletrônica do Mestrado de Educação Ambiental, v. 20, (2008).

SASSERON, Lúcia Helena. Alfabetização Científica no Ensino Fundamental: Estrutura e Indicadores deste processo em sala de aula. São Paulo: 2008.

SASSERON, Lúcia Helena; CARVALHO, Anna Maria Pessoa de. Alfabetização científica: Uma Revisão Bibliográfica. Investigações em Ensino de Ciências. v.16, n. 1, p. 59-77, 2011.

WARD, Helen; RODEN, Judith; HEWLETT, Claire; FOREMAN, Julie. Ensino de Ciências. Tradução Ronaldo Cataldo Costa; consultoria, supervisão e revisão técnica desta edição José Fernando Bitencourt Lomônaco - Porto Alegre: Artmed, 2010. 